\title{
Iminosugar-Cyclopeptoid Conjugates Raise Multivalent Effect in Glycosidase Inhibition at Unprecedented High Levels
}

\author{
Mathieu L. Lepage, ${ }^{[a]}$ Jérémy P. Schneider, ${ }^{[a]}$ Anne Bodlenner, ${ }^{[a]}$ Alessandra Meli, ${ }^{[b]}$ \\ Francesco De Riccardis, ${ }^{[b]}$ Marjorie Schmitt, ${ }^{[c]}$ Céline Tarnus, ${ }^{[c]}$ Nha-Thi Nguyen-Huynh, ${ }^{[d]}$ \\ Yannis-Nicolas Francois, ${ }^{[\mathrm{d}]}$ Emmanuelle Leize-Wagner, ${ }_{1}^{[\mathrm{d}]}$ Catherine Birck, ${ }^{[\mathrm{e}]}$ Alexandra Cousido- \\ Siah $^{[f]}$ Alberto Podjarny, ${ }^{[f]}$ Irene Izzo, ${ }^{[b]}$ and Philippe Compain ${ }^{[[a]}$
}

\begin{abstract}
A series of cyclopeptoid-based iminosugar clusters has been evaluated to finely probe the ligand content-dependent increase in $\alpha$-mannosidase inhibition. This study led to the largest binding enhancement ever reported for an enzyme inhibitor (up to 4700 -fold on a valencycorrected basis), which represents a substantial advance over the multivalent glycosidase inhibitors previously reported. Electron microscopy imaging and analytical data support, for the best multivalent effects, the formation of a strong chelate complex in which two mannosidase molecules are cross-linked by one inhibitor.
\end{abstract}

Multivalency is intuitively recognized by chemists as an appealing strategy for the design of ligands displaying high binding specificity for their receptors. ${ }^{[1]}$ Emblematic examples are found in cells where many key intercellular recognitions events are mediated by multisite carbohydrate-binding proteins (lectins), despite the fact that carbohydrate-lectin interactions are individually weak. ${ }^{[2]}$ The over-amplification of binding affinity

[a] Dr. M. L. Lepage, J. P. Schneider, Dr. A. Bodlenner, Prof. P. Compain Laboratoire de Synthèse Organique et

Molécules Bioactives Université de Strasbourg et CNRS (UMR 7509)

Ecole Européenne de Chimie, Polymères et Matériaux

25 rue Becquerel, 67087 Strasbourg (France)

E-mail:philippe.compain@unistra.fr

[b] A. Meli, Prof. F. De Riccardis, Prof. I. Izzo

Department of Chemistry and Biology, University of Salerno

Via Giovanni Paolo II,132, 84084 Fisciano, Salerno (Italy)

[c] Dr. M. Schmitt, Prof. C. Tarnus

Université de Haute Alsace

Laboratoire de Chimie Organique et Bioorganique (EA4466) ENSCMu, 3, rue Alfred Werner, 68093 Mulhouse Cedex (France)

[d] Dr. N.-T. Nguyen-Huynh, Dr. Y.-N. Francois, Dr. E. Leize-Wagner Laboratoire de Spectrométrie de Masse des Interactions et des Systèmes UMR CNRS 7140, Université de Strasbourg, 67008 Strasbourg (France)

[e] Dr. C. Birck

Structural Biology Platform, CBI-IGBMC

1 rue Laurent Fries, 67404 IIlkirch (France)

[f] A. Cousido-Siah, Dr. A. Podjarny

Department of Integrative Biology, Institut de Génétique et de Biologie Moléculaire et Cellulaire, CNRS, INSERM, UdS 1 rue Laurent Fries, 67404 IIlkirch CEDEX (France)

$\square$ Supporting information and ORCID from the author for this article are iD available on the WWW under http://dx.doi.org/10.1002/chem.201600338. beyond that expected from a concentration increase is referred to as the cluster or multivalent effect. ${ }^{[3]}$ Inspired by Nature, chemists have synthesized a large variety of glycoclusters exhibiting impressive affinity enhancements over the corresponding monovalent lectin ligands. ${ }^{[2,4]}$ Much less effort has been directed so far towards the design of multivalent inhibitors of carbohydrate-processing enzymes despite their therapeutic relevance. Enzymes appear a priori to be less suited for multivalent design since they usually display a single substrate binding site, rendering theoretically impossible chelation mechanisms at the origin of the largest multivalent effects reported for proteins. ${ }^{[2 b, 5]}$ Very recently, the field has experienced a major breakthrough with the discovery of the first strong multivalent effects in glycosidase inhibition observed with iminosugar clusters such as 1 bearing up to 21 DNJ (1-deoxynojirimycin) ligands (Figure 1). ${ }^{[6-10]}$

One of the next, forward-looking steps is to explore the maximum level of affinity enhancement achievable through inhibitory multivalent effects. Beyond breaking new records, identifying such limits, as well as the existence of a plateau ${ }^{[11]}$ in the valency-dependent affinity increase, is expected to shed light on the molecular basis of this recently discovered effect. Our strategy to tackle these objectives was based on iminosugar clusters constructed on large cyclopeptoid cores with incrementally increasing valencies. The challenge of synthesizing large multivalent iminosugars was addressed using a highly convergent strategy based on Cu'-catalyzed azide-alkyne cycloaddition reactions (CuAAC). In this approach, the initial valency of the polyalkyne scaffolds is tripled by the direct grafting of azido-armed trivalent iminosugar dendrons (Scheme 1). ${ }^{[10]}$ Cyclopeptoids ${ }^{[12]}$ appear as ideal tools to both push and precisely probe the limits of multivalent effects. ${ }^{[12,13]}$ In contrast to most scaffolds, they indeed offer synthetic flexibility, allowing the access to clusters with finely incremented valencies. ${ }^{[14,15]}$ Another challenge associated with high-valency systems is that steric crowding of neighboring ligands may limit the multivalent glycosidase binding. ${ }^{[10,11,16]}$ This effect was expected to be overcome by the fact that, in the designed cyclopeptoid-based clusters, the scaffold size grows with the valency (Scheme 1).

To systematically increase valency in six ligand increments, azido-armed trivalent iminosugar 4 was attached by CuAAC onto a series of cyclopeptoids 5 bearing 6 to 16 propargyl groups (Scheme 1). These scaffolds were efficiently prepared 


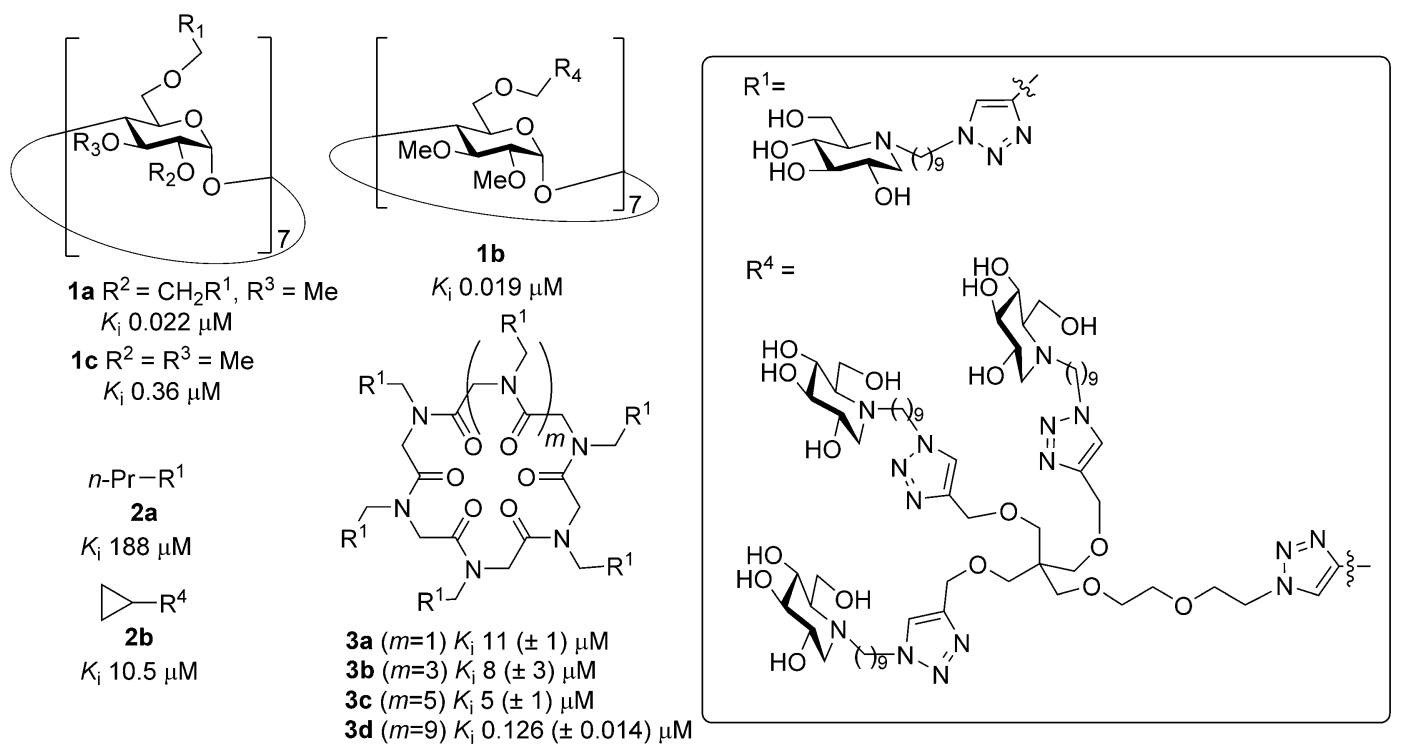

Figure 1. Multi- and monovalent inhibitors of JB $\alpha$-man.

by way of iterative submonomer solid-phase synthesis followed by cyclization in high dilution conditions, leading to ones of the largest cyclopeptoids prepared by head-to-tail coupling strategy (Scheme S3 in the Supporting Information). ${ }^{[13,17]}$ The decisive microwave-assisted CuAAC reaction was found to proceed smoothly to provide the desired 18- to 48-valent peracetylated DNJ clusters 6 in 32 to $77 \%$ yields which were deprotected by using basic anion exchange resin. These compounds were evaluated as inhibitors of Jack bean $\alpha$-mannosidase (JB $\alpha$ man), the glycosidase which has shown the largest responses to multivalent inhibitor presentation to date. ${ }^{[8]}$ The corresponding inhibition constants $\left(K_{i}\right)$ as well as relative inhibition potency $(r p)$ over monovalent control $\mathbf{2} \mathbf{a}$ and valency-corrected $r p$ $(r p / n)$ are collected in Table 1. Due to the structure of neoglycoclusters 7 based on identical trivalent iminosugar subunits, the inhibition potency of trivalent model $\mathbf{2} \mathbf{b}$, obtained by CuAAC coupling between $\mathbf{4}$ and ethynylcyclopropane, has been determined (Scheme S1 in the Supporting Information and Table 1).

In a previous study, ${ }_{1}^{[13]}$ we have shown that 6- to 10-valent cyclopeptoid-based DNJ clusters $\mathbf{3 a - c}$ (Figure 1) displayed modest inhibitory multivalent effects $(r p / n \approx 3-4)$. The addition of eight DNJ units, from $3 \mathrm{c}$ to $7 \mathrm{a}$, led to a dramatic improvement in binding enhancements to reach a $r p / n$ value of 74 . To determine more precisely from which valency significant multivalent effects start to occur, 14-valent iminosugar $\mathbf{3} \mathbf{d}$ was prepared (Scheme S2 in the Supporting Information). The submicromolar $K_{\mathrm{i}}$ value for $\alpha$-mannosidase inhibition obtained for $3 \mathbf{d}$ showed that a take-off in the multivalent effect could be obtained by the addition of only four DNJ units, from 10 to 14 (Table 1). Remarkably, the $r p / n$ values measured for valency from 6 to 36 were found to fit an exponential curve with an astonishing high correlation (Figure $\mathrm{S} 1$ in the Supporting Information). The 36 -valent cluster $\mathbf{7} \mathbf{d}$ was found to display an outstanding relative inhibition potency of about 171000 -fold, far

\begin{tabular}{|c|c|c|c|c|}
\hline Cpd & DNJ unit & $K_{\mathrm{i}}^{[\mathrm{a}]}$ & $r p^{[\mathrm{b}]}$ & $r p / n^{[c]}$ \\
\hline $2 a^{[6]}$ & 1 & $188^{[6]}$ & - & - \\
\hline $2 \mathrm{~b}$ & 3 & $10.5 \pm 1.5$ & 18 & 6 \\
\hline $1 b^{[10]}$ & 21 & $0.019 \pm 0.003^{[10]}$ & 9895 & 471 \\
\hline $3 c^{[13]}$ & 10 & $5 \pm 1^{[13]}$ & 38 & 3.8 \\
\hline $3 d$ & 14 & $0.126 \pm 0.014$ & 1492 & 107 \\
\hline $7 a$ & 18 & $0.142 \pm 0.017$ & 1324 & 74 \\
\hline $7 b$ & 24 & $0.037 \pm 0.012$ & 5081 & 212 \\
\hline $7 c$ & 30 & $0.0099 \pm 0.0028$ & 18990 & 633 \\
\hline $7 d$ & 36 & $0.0011 \pm 0.0004$ & 170909 & 4747 \\
\hline $7 e$ & 42 & $0.0015 \pm 0.0003$ & 125333 & 2984 \\
\hline $7 f$ & 48 & $0.0011 \pm 0.00007$ & 170909 & 3560 \\
\hline
\end{tabular}

[a] Means \pm SD obtained from experiments performed in triplicate. [b] Relative inhibition potency $=K_{\mathrm{i}}$ (monovalent reference $2 \mathrm{a}$ ) $/ K_{\mathrm{i}}$ (cluster). [c] $r p / n=r p /$ number of DNJ units.

from the ones previously observed for clusters 1 -the previous standards in the field (4750-fold vs. 610-fold in a valency-corrected basis). ${ }^{[7,8,10]}$ Beyond glycosidase inhibition, cluster $\mathbf{7} \mathbf{d}^{[18]}$ provides, to our knowledge, the largest binding enhancements ever reported for an enzyme inhibitor. ${ }^{[19,20]}$ Further increasing the number of DNJ ligands (from 36 to 48) did not enhance the inhibitory potency of iminosugar clusters 7 , leading clearly to a plateau in terms of $K_{\mathrm{i}}$ values. To obtain insights into the binding modes underlying the outstandingly large multivalent effect observed, a mechanistic study using three different complementary techniques was performed. The interactions of $\mathrm{JB} \alpha$-man with $\mathbf{7 d}$ were first analyzed using electron microscopy (EM) with negative staining (Figure 2). JB $\alpha$-man is a highmolecular-weight metalloenzyme organized into a homodimer $(\mathrm{LH})_{2}$ of active heterodimers (LH for light and heavy chains) of approximately $66(\mathrm{H})$ and about $44 \mathrm{kDa}(\mathrm{L})$, respectively. ${ }^{[21]}$ In 

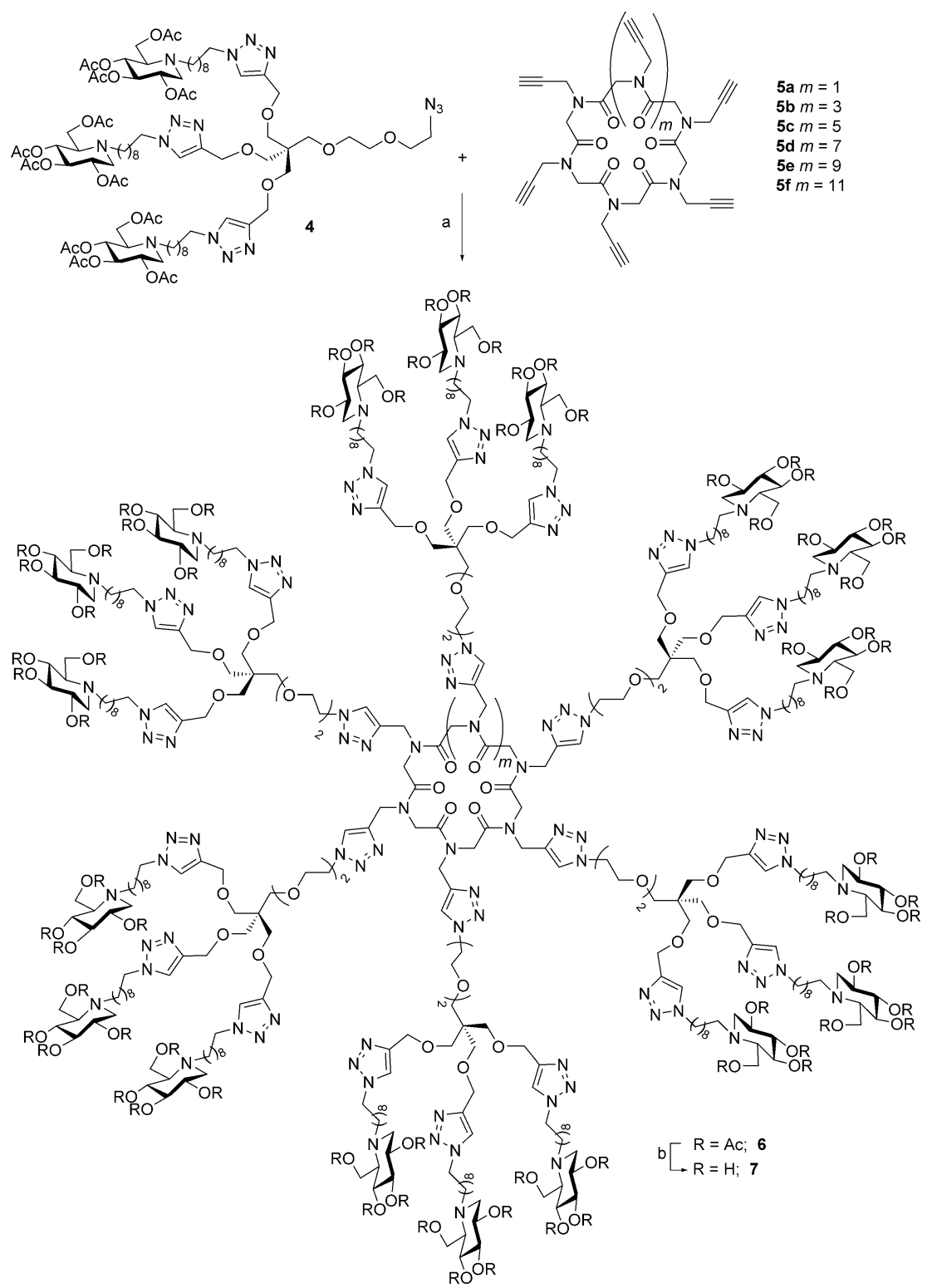

Scheme 1. Reagents and conditions: synthesis of DNJ clusters 7: a) $\mathrm{CuSO}_{4} \cdot 5 \mathrm{H}_{2} \mathrm{O}$ cat., sodium ascorbate, $\mathrm{DMF} / \mathrm{H}_{2} \mathrm{O}(5: 1), \mathrm{MW}, 80^{\circ} \mathrm{C}$ or $90{ }^{\circ} \mathrm{C} ; 6$ a $(m=1) 75 \%$;

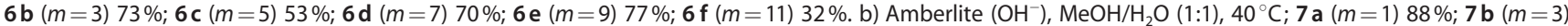
$77 \%$; 7 c $(m=5)$ quant.; $7 \mathbf{d}(m=7) 57 \% ; 7$ e $(m=9) 81 \% ; 7 \mathbf{f}(m=11) 85 \%$.

the case of the mannosidase alone, the image showed clear clusters of approximately $10 \times 20 \mathrm{~nm}$ (Figure 2, left, light-colored frame) matching the size of one homodimer $(\mathrm{LH})_{2}$.

For the complex of JB $\alpha$-man with $\mathbf{7 d}$, several different arrangements are seen, including some approximately $20 x$ $20 \mathrm{~nm}$ in size that may correspond to the interaction of one inhibitor with two tetramers (LH) 2 (Figure 2, right, dark-colored frame). This hypothesis was confirmed by analytical ultracentrifugation sedimentation velocity (AUC-SV) experiments (Figure 3). ${ }^{[22]}$

For $\mathrm{JB} \alpha$-man alone, the main sedimenting species is observed at $9.3 \mathrm{~S}$, corresponding to the tetramer $(\mathrm{LH})_{2}$ with a molar mass estimate of $210 \mathrm{kDa}$ (see the Supporting information). ${ }^{[23]}$ The sedimentation coefficient distribution $c(s)$ showed also a minor species with a sedimentation coefficient value of
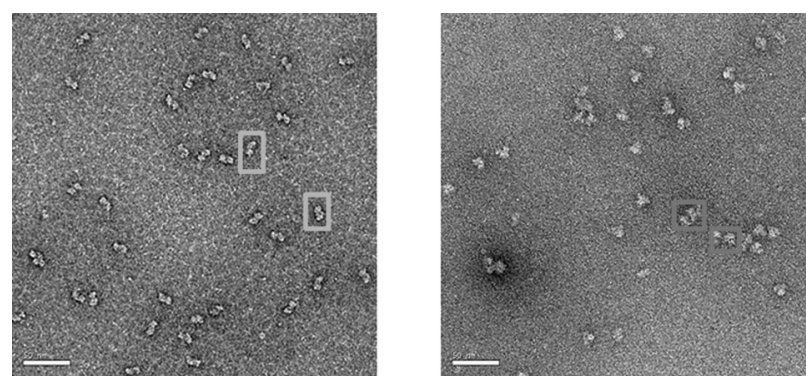

Figure 2. EM pictures of $\mathrm{JB} \alpha$-man (left) and $\mathrm{JB} \alpha$-man interacting with $\mathbf{7 d}$ (right); scale bars $=50 \mathrm{~nm}$.

13.4 $\mathrm{S}$ which may correspond to the association of two JB $\alpha$ man molecules in a $2 \times(\mathrm{LH})_{2}$ complex. The binding of JB $\alpha$-man to $\mathbf{7 d}$ created a broader sedimentation coefficient distribution 

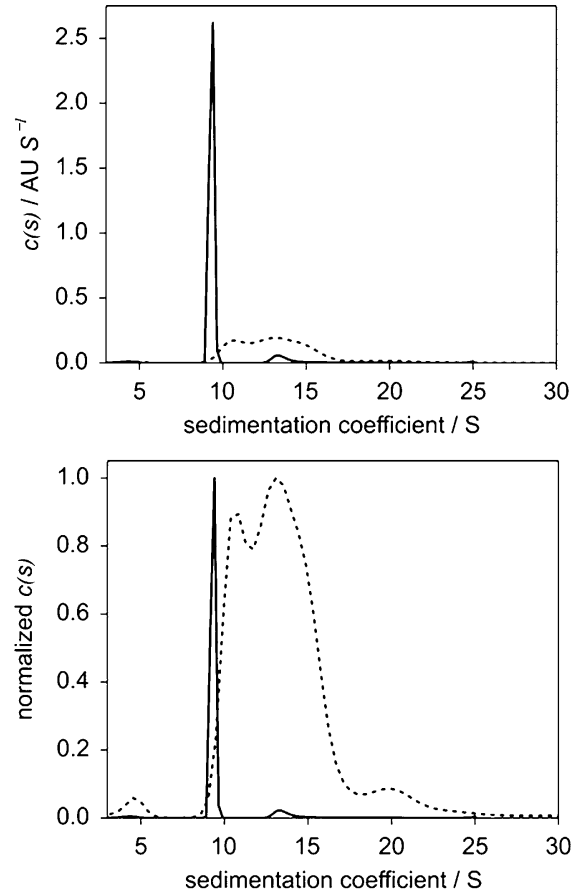

Figure 3. The top panel shows the sedimentation coefficient distribution plot for JB $\alpha$-man (solid line) and for the JB $\alpha$-man:7 d complex (dotted line). The bottom panel shows the same distributions normalized to a maximum of 1.0 .

exhibiting maxima at about $14 \mathrm{~S}$, suggesting the reversible formation of a 2:1 tetramer(LH) ${ }_{2}$-inhibitor complex in dynamic equilibrium with other species. AUC-SV control experiments were also performed with a system displaying a small multivalent effect (DNJ cluster $\mathbf{3} \mathbf{b}, r p / n \sim 3$ ) or for which the binding stoichiometry had been previously determined to be close to one by isothermal titration calorimetry $(\mathbf{1} \mathrm{c}){ }^{[24]}$ In both cases, the major species observed corresponded to the $(\mathrm{LH})_{2}$-inhibitor $1: 1$ complex whereas for the larger cluster $7 \mathbf{a}$, with a $r p / n$ value of 74 , the equilibrium is clearly in favor of the $2: 1(\mathrm{LH})_{2}-$ inhibitor complex (Figure S3 in the Supporting Information). Native electrospray mass spectrometry (ESI-MS) was performed to further confirm the stoichiometry of the noncovalent macromolecular enzyme-inhibitor complex (Figure 4). ${ }^{[25]}$ MS obtained on the native enzyme before and after the inhibitor addition showed the presence of three different multicharged ions patterns (Figure 4). When JB $\alpha$-man is alone in the solution studied (Figure $4 \mathrm{a}$ ), the molecular masses measured correspond to the primal heterodimer $\mathrm{LH}\left(M_{\mathrm{W}}=121.3 \mathrm{kDa}\right)$, the tetramer $(\mathrm{LH})_{2}$ $\left(M_{\mathrm{W}}=242.3 \mathrm{kDa}\right)$ and the association of two tetramers $(\mathrm{LH})_{2}$ $\left(M_{\mathrm{W}}=484.9 \mathrm{kDa}\right)$, respectively (see the Supporting information). After addition of the inhibitor $7 \mathrm{~d}\left(M_{\mathrm{W}}=17.4 \mathrm{kDa}\right.$, Figure $\left.4 \mathrm{~b}\right)$, both enzyme-inhibitor complexes are observed with a $17 \mathrm{kDa}$ shift $\left(M_{\mathrm{W}}=259.9 \mathrm{kDa}\right.$ for the $1: 1$ complex and $M_{\mathrm{W}}=501.9 \mathrm{kDa}$ for the 2:1 complex).

Based on the corroborating results obtained with three different techniques, the outstanding multivalent effects observed may be rationalized by the formation of a strong chelate complex in which the inhibitor cross-links two tetramers $(\mathrm{LH})_{2}$ (Figure 5). Such a complex would involve reversible active-site specific interactions but also protein-protein interactions between two tetramers. Increasing the valency and the global size of the scaffold shifts the equilibrium of the different

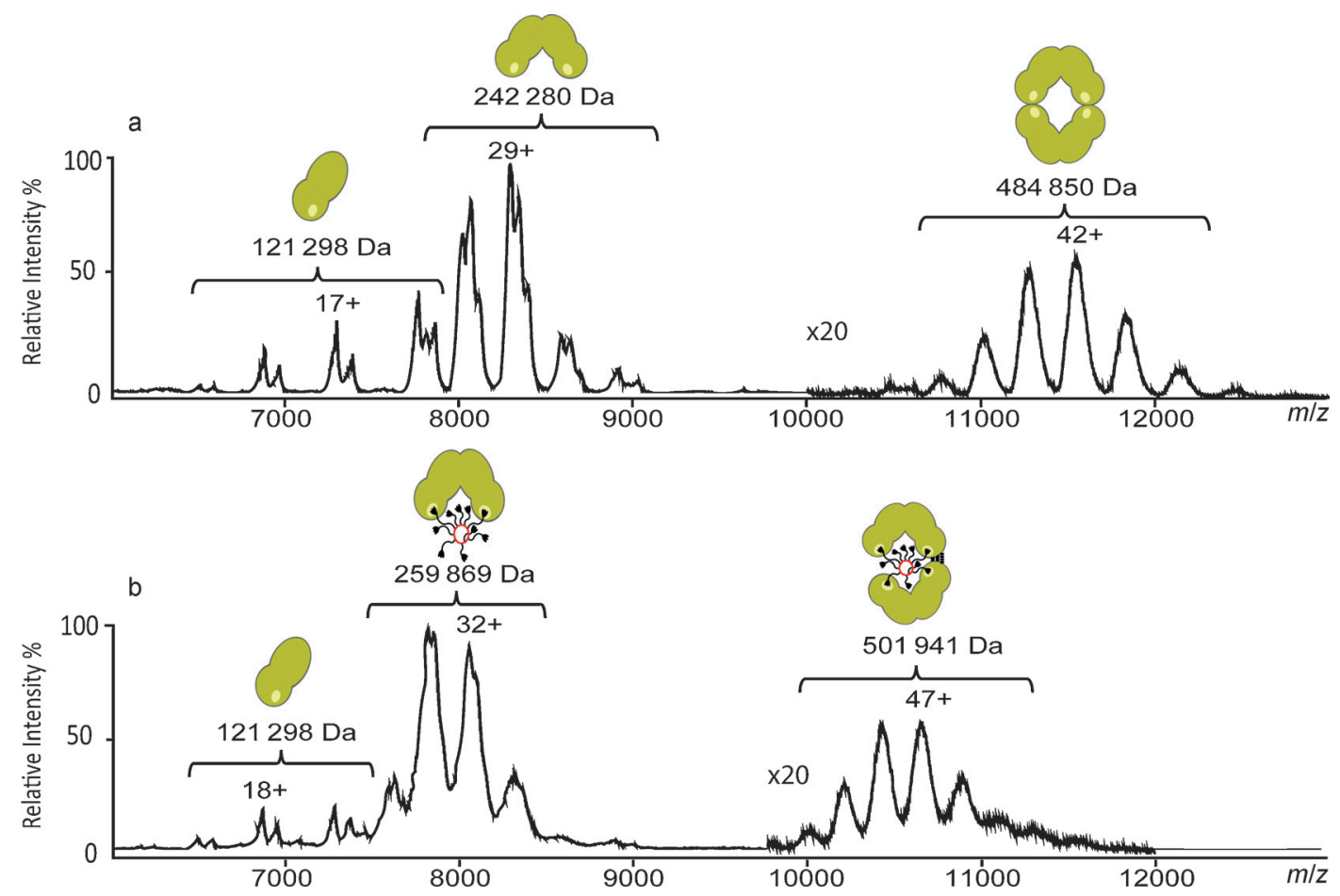

Figure 4. Native ESI-MS spectra for: a) JB $\alpha$-man, and b) JB $\alpha$-man interacting with $\mathbf{7} \mathbf{d}$. Multicharged ions patterns are labeled with the corresponding enzyme and enzyme-inhibitor complexes. 


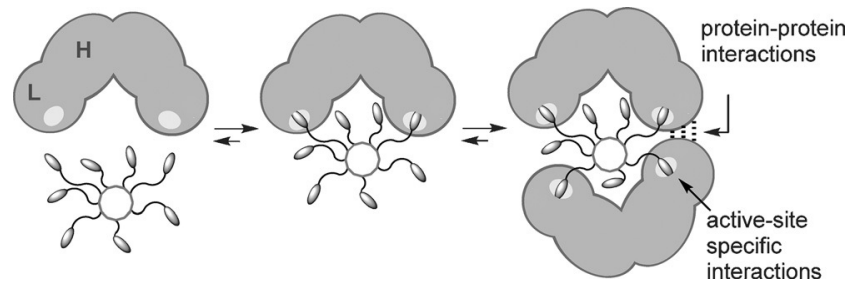

Figure 5. Cartoon representation of a large reversible multivalent inhibitor forming chelate complexes with $\mathrm{JB} \alpha$-man.

species in solution towards the 2:1 tetramer-inhibitor complex even in the presence of an excess of inhibitor showing that the $2: 1$ sandwich may be thermodynamically favored. The implications of these findings for the design of multivalent inhibitors and the identification from the protein data bank of other multimeric glycosidases responsive to multivalency are currently under investigation in our laboratories.

\section{Acknowledgements}

This work was supported by the CNRS, the University of Strasbourg, Instruct (part of the European Strategy Forum of Research Infrastructures), the French Infrastructure for Integrated Structural Biology, ANR-10-INSB-05-01 and doctoral fellowships from the French Department of Research to M.L. and N.T.N.H. The authors express their gratitude to Jean-Francois Menetret for EM measurements (IGBMC). We thank also the University of Salerno (FARB) and the Italian MIUR (PRIN20109Z2XRJ_006) for financial support.

\section{Keywords: glycopeptides • glycosidases • iminosugars} inhibitors $\cdot$ multivalency

[1] S.-K. Choi, Synthetic Multivalent Molecules: Concepts and Biomedical Applications, Wiley, New Jersey, 2004.

[2] For recent reviews see: a) D. Deniaud, K. Julienne, S. G. Gouin, Org. Biomol. Chem. 2011, 9, 966-979; b) R. J. Pieters, Org. Biomol. Chem. 2009, 7, 2013-2025; c) A. Martínez, C. Ortiz Mellet, J. M. García Fernández, Chem. Soc. Rev. 2013, 42, 4746-4773; d) Y. M. Chabre, R. Roy, Chem. Soc. Rev. 2013, 42, 4657-4470; e) T. K. Dam, C. F. Brewer, Adv. Carbohydr. Chem. Biochem. 2010, 63, 139-164.

[3] Y. C. Lee, R. T. Lee, Acc. Chem. Res. 1995, 28, 321 - 327.

[4] P. I. Kitov, J. M. Sadowska, G. Mulvey, G. D. Armstrong, H. Ling, N. S. Pannu, R. J. Read, D. R. Bundle, Nature 2000, 403, 669-672.

[5] a) M. Mammen, S.-K. Choi, G. M. Withesides, Angew. Chem. Int. Ed. 1998, 37, 2754-2794; Angew. Chem. 1998, 110, 2908-2953; b) J. E. Gestwicki, C. W. Cairo, L. E. Strong, K. A. Oetjen, L. L. Kiessling, J. Am. Chem. Soc. 2002, 124, 14922-14933; c) V. Wittmann, R. J. Pieters, Chem. Soc. Rev. 2013, 42, 4492-4503.

[6] P. Compain, C. Decroocq, J. lehl, M. Holler, D. Hazelard, T. Mena Barragán, C. Ortiz Mellet, J.-F. Nierengarten, Angew. Chem. Int. Ed. 2010, 49, 5753-5756; Angew. Chem. 2010, 122, 5889-5892.

[7] C. Decroocq, D. Rodríguez-Lucena, V. Russo, T. Mena Barragán, C. Ortiz Mellet, P. Compain, Chem. Eur. J. 2011, 17, 13825-13831.
[8] For reviews see: a) P. Compain, A. Bodlenner, ChemBioChem 2014, 15, 1239-1251; b) S. Gouin, Chem. Eur. J. 2014, 20, 11616-11628; c) R. Zelli, J.-F. Longevial, P. Dumy, A. Marra, New J. Chem. 2015, 39, 5050-5074.

[9] For an application to glycosidases of therapeutic interest in cells see: $P$. Compain, C. Decroocq, A. Joosten, J. de Sousa, D. Rodriguez-Lucena, T. D. Butters, J. Bertrand, R. Clément, C. Boinot, F. Becq, C. Norez, ChemBioChem 2013, 14, 2050-2058.

[10] A. Joosten, J. P. Schneider, M. L. Lepage, C. Tarnus, A. Bodlenner, P. Compain, Eur. J. Org. Chem. 2014, 1866-1872.

[11] The existence of such plateau phenomena has been reported in the field of carbohydrate-lectin interactions: a) D. Pagé, D. Zanini, R. Roy, Bioorg. Med. Chem. 1996, 4, 1949-1961; b) M. Kanai, K. H. Mortell, L. L. Kiessling, J. Am. Chem. Soc. 1997, 119, 9931-9932; c) P. R. Ashton, E. F. Hounsell, N. Jayaraman, T. M. Nilsen, N. Spencer, J. F. Stoddart, M. Young, J. Org. Chem. 1998, 63, 3429-3437.

[12] a) I. Izzo, G. Ianniello, C. De Cola, B. Nardone, L. Erra, G. Vaughan, C. Tedesco, F. De Riccardis, Org. Lett. 2013, 15, 598-601; b) B. Yoo, S. B. Y. Shin, M. Lace Huang, K. Kirshenbaum, Chem. Eur. J. 2010, 16, 55285537 ; c) S. Shin, B. Yoo, L. J. Todaro, K. Kirshenbaum, J. Am. Chem. Soc. 2007, 129, 3218-3225.

[13] M. L. Lepage, A. Meli, A. Bodlenner, C. Tarnus, F. De Riccardis, I. Izzo, P. Compain, Beilstein J. Org. Chem. 2014, 10, 1406-1412.

[14] T. Szekely, O. Roy, S. Faure, C. Taillefumier, Eur. J. Org. Chem. 2014, $5641-5657$.

[15] a) I. Izzo, C. De Cola, F. De Riccardis, Heterocycles 2011, 82, 981 -1006; b) D. Comegna, F. De Riccardis, Org. Lett. 2009, 11, 3898-3901.

[16] H. Zheng, X. Du, Biochim. Biophys. Acta Biomembr. 2013, 1828, $792-$ 800.

[17] R. N. Zuckermann, J. M. Kerr, S. B. H. Kent, W. H. Moos, J. Am. Chem. Soc. 1992, 114, 10646-10647.

[18] A low content of residual copper ions ( $60 \mathrm{ppm})$ was measured in $\mathbf{7} \mathbf{d}$ by inductively coupled plasma atomic emission spectroscopy.

[19] Moroder et al. reported that divalent ligands bridging simultaneously two catalytic sites of human $\beta$-tryptase were up to 68000 -fold more potent than the corresponding monovalent inhibitor: N. Schaschke, G. Matschiner, F. Zettl, U. Marquardt, A. Bergner, W. Bode, C. P. Sommerhoff, L. Moroder, Chem. Biol. 2001, 8, 313-327.

[20] A rp/n value of 120 has been recently reported for a dextran-based polymeric iminosugar with an average valency of 902: Y. Brissonnet, S. Ladevèze, D. Tezé, E. Fabre, D. Deniaud, F. Daligault, C. Tellier, S. Sestak, M. Remaud-Simeon, G. Potocki-Veronese, S. G. Gouin, Bioconjugate Chem. 2015, 26, 766-772.

[21] The molecular weight of $\mathrm{JB} \alpha-\mathrm{man}$ has been previously estimated to be between 220 and 260 kDa: a) A. Kumar, S. M. Gaikwad, Int. J. Biol. Macromol. 2011, 49, 1066-1071; b) B. S. Gnanesh Kumar, G. Pohlentz, M. Schulte, M. Mormann, N. S. Kumar, Glycobiology 2014, 24, 252-261; c) S. M. Snaith, Biochem. J. 1975, 147, 83-90; d) S. Howard, S. He, S. G. Withers, J. Biol. Chem. 1998, 273, 2067-2072.

[22] For selected reviews on AUC-SV see: a) J. L. Cole, J. W. Lary, T. Moody, T. M. Laue, Methods Cell Biol. 2008, 84, 143-179; b) J. Lebowitz, M. S. Lewis, P. Shuck, Protein Sci. 2009, 11, 2067-2079; c) P. Schuck, Biophys. J. 2010, 98, 2005-2013.

[23] The molar mass distribution $c(M)$ allow to obtain molar mass estimates of the sedimenting species frequently within $10 \%$ of the correct value see: J. Dam, P. Schuck, Methods Enzymol. 2004, 384, 185-212.

[24] C. Decroocq, A. Joosten, R. Sergent, T. Mena Barragán, C. Ortiz Mellet, P. Compain, ChemBioChem 2013, 14, 2038-2049.

[25] For a review on MS as a tool to quantify protein interactions see: $\mathrm{S}$. Hopper, C. V. Robinson, Angew. Chem. Int. Ed. 2014, 53, 14002-14015; Angew. Chem. 2014, 126, 14224-14238.

Received: January 25, 2016

Published online on February 24, 2016 